\title{
Construction of Learning Behavioral Engagement Model for MOOCs Platform Based on Data Analysis *
}

\author{
Gengxin Sun ${ }^{1}$ \\ Qingdao University
}

\author{
Sheng Bin $^{2}$ \\ Qingdao University
}

\begin{abstract}
Learning behavioral engagement is an important learning feature that affects students' learning achievement and persistence. As the main driving force of students' actual performance, there is not effective evaluation model of learning behavioral engagement for MOOCs platform. It is helpful to observe the change rule of students' participation and activity by analyzing the data of learning behavioral engagement. In this paper, the online study data and feedback learning behavioral engagement data from four MOOCs course were analyzed, and the predictive effect of behavior variables on learning behavioral engagement were studied. According to the results of data analysis, persistence, reflection, initiative and concentration are identified as the assessment dimensions of level which can represent learning behavioral engagement. Based on this, the evaluation model based on MOOCs platform is constructed. The establishment of the model can lay the foundation for the design of related evaluation and analysis tools.
\end{abstract}

\section{Keywords}

Learning Behavioral Engagement $\bullet$ MOOCs • Data Analysis $•$ Evaluation Framework

\footnotetext{
*This work is supported by the Humanity and Social Science Youth foundation of Ministry of Education of China (grant no.15YJC860001). This research is also supported by the Natural Science Foundation of Shandong Province (grant no. ZR2017MG011), Shandong Education Science 13th Five-Year plan project (grant no. BYK2017006), Statistical Science Research Project of China (grant no. 2015LZ20, 2017LZ38) and Humanities and Social Sciences Foundation of Shandong Province (grant no.17CHLJ16), Humanities and Social Sciences Foundation of Qingdao (grant no. QDSKL1701074).

${ }^{1}$ Correspondence to: Gengxin Sun $(\mathrm{PhD})$, School of Data Science and Software Engineering, Qingdao University, Qingdao 266071, China. Email: sungengxin@qdu.edu.cn

${ }^{2}$ School of Data Science and Software Engineering, Qingdao University, Qingdao 266071, China. Email: binsheng@qdu.edu.cn
}

Citation: Sun, G X., \& Bin, S. (2018). Construction of Learning Behavioral Engagement Model for MOOCs Platform
Based on Data Analysis. Educational Sciences: Theory \& Practice, 18(5), $2206-2216$.
http://dx.doi.org/10.12738/estp.2018.5.120


As the main driving force of learners' actual performance, behavioral engagement refers to a more active, lasting and effective behavior state. It is the result of learners' information exchange activities with learning resources under the control of tools, learning methods and learning tasks by means of learning space (Skinner, Furrer, Marchand, \& Kindermann, 2008). Many studies have shown that learning behavioral engagement is closely related to learning performance (Bakker, Vergel, \& Kuntze, 2015; Hughes, \& Dobbins, 2015; Uztosun, Skinner, \& Cadorath, 2017; Nicart, Zanuttini, Grilhères, Giroux, \& Saval, 2017; Hammond, 2014), and it is an important factor affecting academic achievement.

According to the theoretical model of learning behavioral engagement, under the stimulation of learning goals and motivations learners use different adaptive adjustment strategies, which can lead to corresponding learning behavioral engagement. It is reflected in the improvement of learning performance and the achievement of learning goals (Liu, Calvo, Pardo, \& Martin, 2015). Therefore, the study of learning behavioral engagement can focus on the adaptive adjustment process of learners to information exchange activities.

As a new teaching technology, MOOC contains the concept of "classroom", which has unique educational significance and virtuality. Similar to the traditional classroom teaching mode, the "classroom" in MOOC is also organized by teachers to teach teaching contents to students. The teaching process also includes attracting attention, informing learning goals, stimulating recall of previously learned content, presenting learning materials, providing learning guidance, eliciting behavior, providing feedback, evaluating behavior, promoting retention and transfer, etc (Leng, Wu, \& Gu, 2017). The difference between MOOC and traditional classroom teaching is that the process of teaching and learning in MOOC is conducted online remotely, and the interaction between teachers and students in the process of MOOC teaching is non-real-time communication.

With the rise and development of MOOC education, a large number of diverse learning data are generated and recorded, it provides valuable data for monitoring and evaluating learning behavioral engagement. Compared with the traditional content-centered learning, students' performance in MOOC can reflect their overall learning behavioral engagement state and preference to a greater extent. Therefore, the MOOC data can be used to evaluate, diagnose and regulate learning behavioral engagement of students in real time by constructing the corresponding evaluation model. The kind of automatic evaluation and monitoring for learning behavioral engagement is not only the need for educational institutions to promote students' learning, but also the inevitable trend for educational institutions to strengthen the intelligence of teaching guidance and the personalized learning support. The purpose of this study is to explore an automatic evaluation model for learners' learning behavioral engagement based on MOOC behavioral data, so as to provide a basis for intelligent monitoring and personalized support of learning behavioral engagement.

\section{Related works}

Learning behavioral engagement is not only an important factor affecting academic achievement and teaching reform (Fredricks, Blumenfeld, \& Paris, 2004), but also it reflects the support degree and promotion of educational institutions for students' learning (George, 2003). In the 80s of last century, Mosher et al. put 
Sun, Bin / Construction of Learning Behavioral Engagement Model for MOOCs Platform Based on Data Analysis.

forward the term "learning engagement" firstly (Mosher, \& Macgowan, 1985). Finn proposed a "participationidentification " model based on the perspective of withdraw and completion, and he regarded learning behavioral engagement as a multi-dimensional concept. According to the "participation-identification " model, learning engagement could be conceptualized as the following continuous process: participation, school success, identification, nonparticipation, poor school performance and emotional withdrawal (Finn, 1989).

Miles believed that learning behavioral engagement referred to task involvement time, learning task persistence, effort and participation, which were simultaneously or individually associated with academic achievement or cognitive ability (Miles, \& Stipek, 2006). Li, \& Lerner, (2013) used the autoregressive lagged effects models to evaluate the relationship between three dimensions of learning behavioral engagement model. The results showed that learning behavioral engagement had two-way relationship with affective engagement and cognitive engagement, and learning behavioral engagement can influence and predict subsequent affective and cognitive engagement. Rose believed that learning behavioral engagement was a prerequisite for skill development, positive social interaction and emotional engagement (Rose-Krasnor, 2010).

A large number of studies have focused on index analysis of learning behavioral engagement in traditional educational environments. Ten representative indexes of learning behavioral engagement are summarized in Table 1.

Table 1

Measuring Indexes of Learning Behavioral Engagement

\begin{tabular}{ll}
\hline Researchers & \multicolumn{1}{c}{ Measuring indexes } \\
\hline Ladd (1997) & $\begin{array}{l}\text { Listen carefully to teachers' guidance, undertake the responsibility of } \\
\text { teachers to arrange tasks, seek challenges and learn independence }\end{array}$ \\
$\begin{array}{l}\text { Fredricks, Blumenfeld, \& } \\
\text { Paris (2004) }\end{array}$ & performance of classroom activities \\
$\begin{array}{l}\text { Ouimet, \& Smallwood, } \\
\text { (2005) }\end{array}$ & skills, participation and performance \\
Martin (2011) & persistence, planning and task management \\
Skinner, Kindermann, \& & efforts, perseverance, intensity, attention, absorption and participation \\
Furrer (2009) & \\
Luo, Hughes, Liew, \& Kwok & classroom focus, response rules and requirements, positive action \\
(2009) & attention, effort and task continuity in task process \\
Reeve (2012) & task time, learning behavior, classroom participation and discussion \\
Mahatmya, Lohman, & active participation, dedication and persistence \\
Lam, et al. (2014) & teacher-student interaction, active learning, cooperative learning, trial \\
Hamane (2014) & feedback, task time \\
\hline
\end{tabular}

Because learning behavioral engagement is the result of interaction between learners and learning environment, there are some limitations in the existing measuring indexes system. By comparing the related definitions and scales of traditional scene to construct the indexes system, there is a lack of understanding of the particularity of online learning and a lack of description and interpretation from the perspective of learning process, which makes it difficult to reflect the essential characteristics of earning behavioral engagement. Generally speaking, in the absence of research on the nature, internal mechanism and theoretical model of learning behavioral engagement, researchers have not yet established a systematic, procedural and valid framework, and it is difficult to truly characterize the level of learning behavioral engagement. 


\section{Data analysis of learning behavioral engagement based on MOOCs platform}

\section{Evaluation framework of learning behavioral engagement based on MOOC platform}

MOOC platform can record 16 indexes, such as the start and end time of each learning activity, learning time of VOD courseware, after-school test scores, the depth of learning notes, the length of learning notes and so on. The main indexes and their calculation methods are explained as follow:

(1) Total learning time and learning times

The platform records the weighting value of time and frequency between login and logout.

(2) Learning interval and regularity

The time interval between two adjacent logins for learners can be represented as $\Delta t$. For each learner, the platform will generate some values, such as, $\Delta 1, \Delta 2, \ldots, \Delta \mathrm{n}$. The mean value of $\Delta \mathrm{t}$ can be used to calculate learning interval, and standard deviation of $\Delta \mathrm{t}$ can be used to measure learning regularity.

(3) Depth and length of learning notes

Learners can call learning notes at any time. Recording can be in the form of input, handwriting or audio and video. The platform records the level (depth) of notes and the length of strings, and the length of learning notes can be calculated through the average length of strings.

(4) After-school test scores

The after-class test mainly includes semi-open and open expanded problems. A considerable proportion requires learners to draw mind maps, review the context of knowledge points in the classroom, or examine learners' deep understanding of the content. The final score is given through the form of platform approval and teacher correction.

(5) Number of questions, answers and topics recommended by learners

Learners can vote between teachers and learners, publish learning topics and reply at any possible learning stage by using the interactive answering system.

(6) Interactive display times

Learners can share their terminals with others in the same screen for demonstration, operation or display.

(7) Timely assessment of time and score

Timely assessment is based on objective questions. In the MOOC platform, the teacher pushes the questions to the learners, and the learners answers the questions immediately after achieving instructions. The timely assessment time is defined as the designated time threshold of teachers minus the time for learners to answer. 
Sun, Bin / Construction of Learning Behavioral Engagement Model for MOOCs Platform Based on Data Analysis.

(8) Courseware VOD score

Courseware VOD is presented in two forms: micro-video and interactive electronic teaching material. Teachers add objective questions, interactive time points, and set relevant weights. In the process of answering, the platform will give a comprehensive score according to the accuracy of the learner's answer, the number of attempts and the number of goals achieved.

Table 2

Evaluation Framework of Learning Behavioral Engagement Based on MOOC Platform

\begin{tabular}{|c|c|c|c|c|}
\hline Dimension & Learning activities & Scene & $\begin{array}{c}\text { Evaluation } \\
\text { criteria }\end{array}$ & Indexes \\
\hline \multirow{4}{*}{ sustainability } & \multirow{4}{*}{$\begin{array}{l}\text { Learning from MOOC } \\
\text { platform }\end{array}$} & \multirow{4}{*}{$\begin{array}{l}\text { before-class, } \\
\text { during-class, } \\
\text { after-class }\end{array}$} & time & total learning time \\
\hline & & & number & total learning times \\
\hline & & & time & learning interval \\
\hline & & & time & learning regularity \\
\hline \multirow{3}{*}{ reflection } & \multirow{2}{*}{$\begin{array}{l}\text { Learners use learning notes to } \\
\text { record related problems in } \\
\text { learning }\end{array}$} & \multirow{2}{*}{$\begin{array}{l}\text { before-class, } \\
\text { during-class, } \\
\text { after-class }\end{array}$} & number & $\begin{array}{l}\text { depth of learning } \\
\text { notes }\end{array}$ \\
\hline & & & number & $\begin{array}{l}\text { length of learning } \\
\text { notes }\end{array}$ \\
\hline & $\begin{array}{l}\text { Learners use the assessment } \\
\text { test to answer questions of } \\
\text { expansion and migration }\end{array}$ & after-class & score & $\begin{array}{l}\text { after-school test } \\
\text { scores }\end{array}$ \\
\hline \multirow{6}{*}{ initiative } & $\begin{array}{l}\text { Learners raise questions in } \\
\text { text form }\end{array}$ & $\begin{array}{l}\text { before-class, } \\
\text { during-class, } \\
\text { after-class }\end{array}$ & number & $\begin{array}{l}\text { number of } \\
\text { questions in text } \\
\text { form }\end{array}$ \\
\hline & $\begin{array}{l}\text { Learners raise questions in } \\
\text { Multi-media form }\end{array}$ & $\begin{array}{l}\text { before-class, } \\
\text { during-class, } \\
\text { after-class } \\
\end{array}$ & number & $\begin{array}{l}\text { number of } \\
\text { questions in Multi- } \\
\text { media form }\end{array}$ \\
\hline & $\begin{array}{l}\text { Learners answer teachers' } \\
\text { questions in text form }\end{array}$ & $\begin{array}{l}\text { before-class, } \\
\text { during-class, } \\
\text { after-class }\end{array}$ & number & $\begin{array}{l}\text { number of answers } \\
\text { in text form }\end{array}$ \\
\hline & $\begin{array}{l}\text { Learners answer teachers' } \\
\text { questions in Multi-media form }\end{array}$ & $\begin{array}{l}\text { before-class, } \\
\text { during-class, } \\
\text { after-class }\end{array}$ & number & $\begin{array}{l}\text { number of answers } \\
\text { in Multi-media } \\
\text { form }\end{array}$ \\
\hline & Learners demonstrate or share & during-class & number & $\begin{array}{l}\text { interactive display } \\
\text { times }\end{array}$ \\
\hline & $\begin{array}{l}\text { Learners answers the } \\
\text { questions immediately after } \\
\text { achieving instructions }\end{array}$ & during-class & time & $\begin{array}{l}\text { timely assessment } \\
\text { of time }\end{array}$ \\
\hline \multirow{2}{*}{ concentration } & $\begin{array}{l}\text { Learners learn from } \\
\text { Courseware VOD }\end{array}$ & $\begin{array}{l}\text { before-class, } \\
\text { after-class }\end{array}$ & time & $\begin{array}{l}\text { courseware VOD } \\
\text { score }\end{array}$ \\
\hline & $\begin{array}{l}\text { Learners answers the } \\
\text { questions }\end{array}$ & during-class & number & $\begin{array}{l}\text { timely assessment } \\
\text { of time score }\end{array}$ \\
\hline
\end{tabular}

Mapping relationship "evaluation dimension-learning activity" is constructed, different dimensions of learning behavioral engagement can be resolved into learning activities in different learning scenarios. According to above indexes, an evaluation framework "Evaluating dimensions - Learning activities - Platform indexes " for learning behavioral engagement is proposed as shown in Table 2.

\section{Empirical study of evaluation framework based on data analysis}

In the empirical data with a sample size of 5756 students, three representative MOOC courses were selected. The weighted scores of the three courses are used as a measure of learning outcomes. Score included the final grade and classroom performance, it can reflect learning outcomes of learners more authentically. 
Sun, Bin / Construction of Learning Behavioral Engagement Model for MOOCs Platform Based on Data Analysis.

Exploratory factor analysis (EFA) and confirmatory factor analysis (CFA) are important evaluation methods for empirical data analysis. The sample $\mathrm{n}=5756$ is divided into two parts randomly, each sample contains 2878 learners. One sample uses correlation analysis and exploratory factor analysis to construct model indexes, and the other sample carries out confirmatory factor analysis. Finally, based on the whole data set, principal component regression was used to examine the relationship between different engagement factors and learning outcomes. The factor load of "Interactive display times" is 0.375 , so it can be considered to delete.

Factor analysis is carried out again after deleting the "Interactive display times" factor. The eigenvalues of the 4 common factors were $3.804,2.396,1.947,1.583$ respectively. The accumulation variance explained rate of four factor was $64.90 \%$. After using the maximum variance method of orthogonal axis, the positions of all factors are relatively unchanged. The eigenvalues of the 4 common factors were $3.156,2.712,1.985,1.877$. The cumulative contribution rate of 4 factors remained unchanged. The data analysis shows that the 4 factors can explain the role of variables very well. The factor load is between 0.625 and 0.930 , which indicates that latent variables can effectively reflect all variables. Exploratory factor analysis of evaluation framework is shown in Table 3.

Table 3

Exploratory Factor Analysis of Evaluation Framework

\begin{tabular}{llc}
\hline Factor & \multicolumn{1}{c}{ Indexes } & Factor load \\
\hline \multirow{3}{*}{ Sustainability } & Learning interval & 0.927 \\
& Total learning times & 0.857 \\
& Total learning time & 0.819 \\
& Learning regularity & 0.796 \\
\hline \multirow{2}{*}{ Initiative } & Number of questions in text form & 0.807 \\
& Number of questions in Multi-media form & 0.756 \\
& Number of answers in text form & 0.718 \\
& Number of answers in Multi-media form & 0.656 \\
Concentration & Timely assessment of time & 0.632 \\
\hline \multirow{2}{*}{ Reflection } & Timely assessment of score & 0.852 \\
& Courseware VOD score & 0.792 \\
\hline
\end{tabular}

From Table 3 we can see that factor one consisted of four indexes: learning interval, total learning times, total learning time and learning regularity. Its load is between 0.796 and 0.927 . It is the primary factor of learning behavioral engagement, and it is defined as "sustainability". Factor two consisted of five indexes: number of questions in text form, number of questions in Multi-media form, number of answers in text form, number of answers in Multi-media form and timely assessment of time. Its load is between 0.632 and 0.807. The factor is defined as "initiative". Factor three consisted of two indexes: Timely assessment of score and Courseware VOD score. Its load is between 0.792 and 0.852 . The factor is defined as "concentration". Factor four consisted of three indexes: Depth of learning notes, Length of learning notes and After-school test scores. Its load is between 0.726 and 0.811 . The factor is defined as "reflection".

The maximum likelihood estimation method is used to investigate the fitting degree of data and structure of the theoretical system. The results are shown in Figure 1.

In the confirmatory factor analysis, the simple fitness index includes $\chi^{2} / d f$, PCFI, the absolute fitness index includes RMSEA and GFI, the value-added adaptation index includes IFI, TLI and CFI. In our study, $\chi^{2} / d f$ is 
Sun, Bin / Construction of Learning Behavioral Engagement Model for MOOCs Platform Based on Data Analysis.

2.918 , the value is less than 3 . PCFI is 0.632 , the value is more than 0.5 . RMSEA is 0.069 , the value is less than 0.07. GFI is 0.918 , the value is more than 0.9. IFI is 0.931 , TLI is 0.911 , and CFI is 0.936 , their values are all more than 0.5 . The standardized path coefficient is between 0.60 and 0.94 . The fitting index of the model is good, it shows that the theoretical framework has good validity.

To further explore the structure of the index framework, constructive reliability (CR) was used to examine whether the indexes in each latent variable were consistent. The formula of CR is as follows:

$$
\mathrm{CR}=\sum \lambda^{2} /\left(\sum \lambda^{2}+\sum \delta\right)
$$

Where $\delta$ represents the variation explained by the error variable of each index. The construction reliability of the evaluation framework is 0.949 through computation, it is much higher than 0.70 , which means that the construction reliability is relatively good.

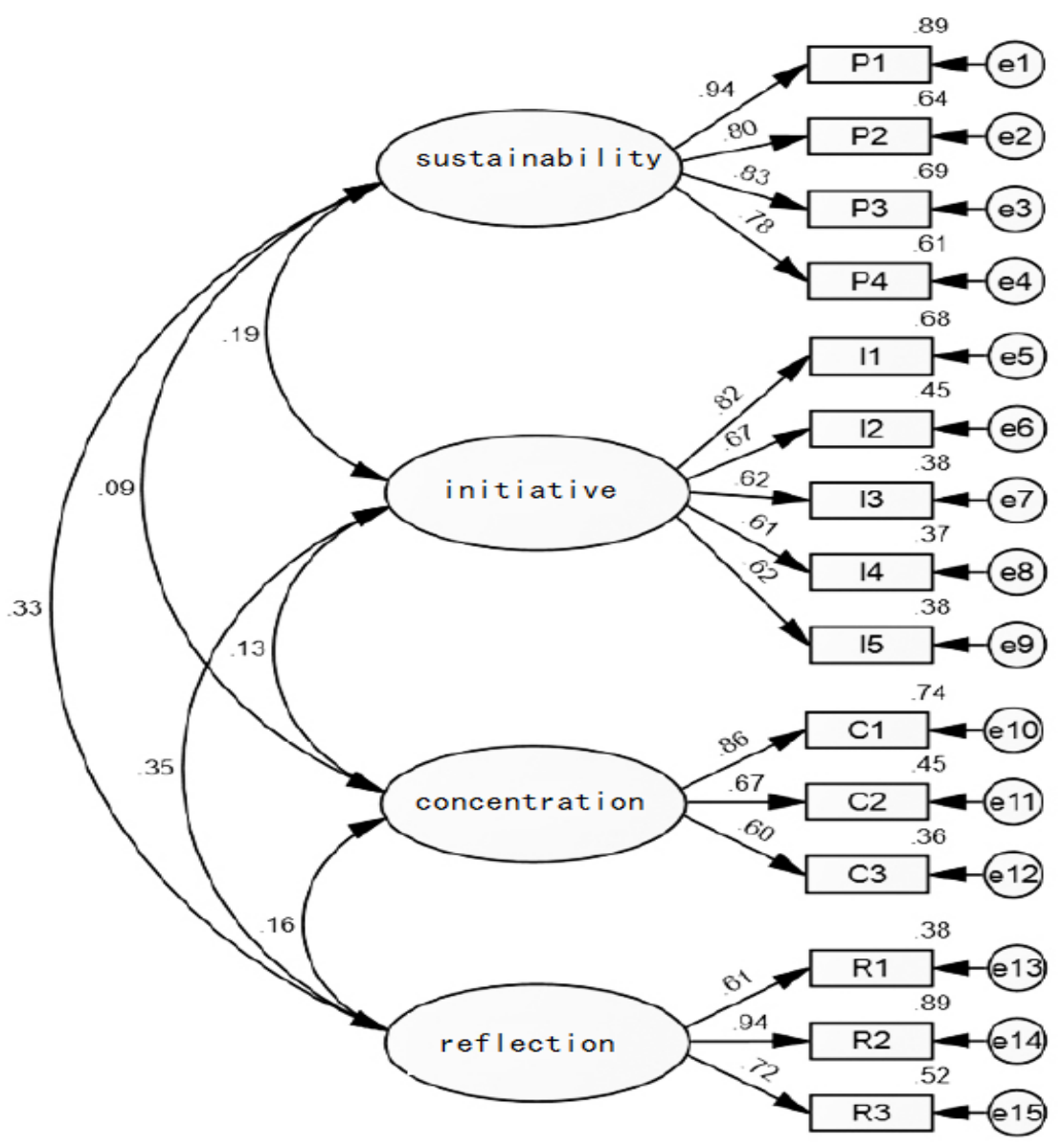

Figure 1. Index structure of learning behavioral engagement framework 


\section{Construction of learning behavioral engagement periodic feedback model}

Based on empirical data analysis, the learning behavioral engagement periodic feedback model is proposed. The periodic feedback process of the model is shown in Figure 2.

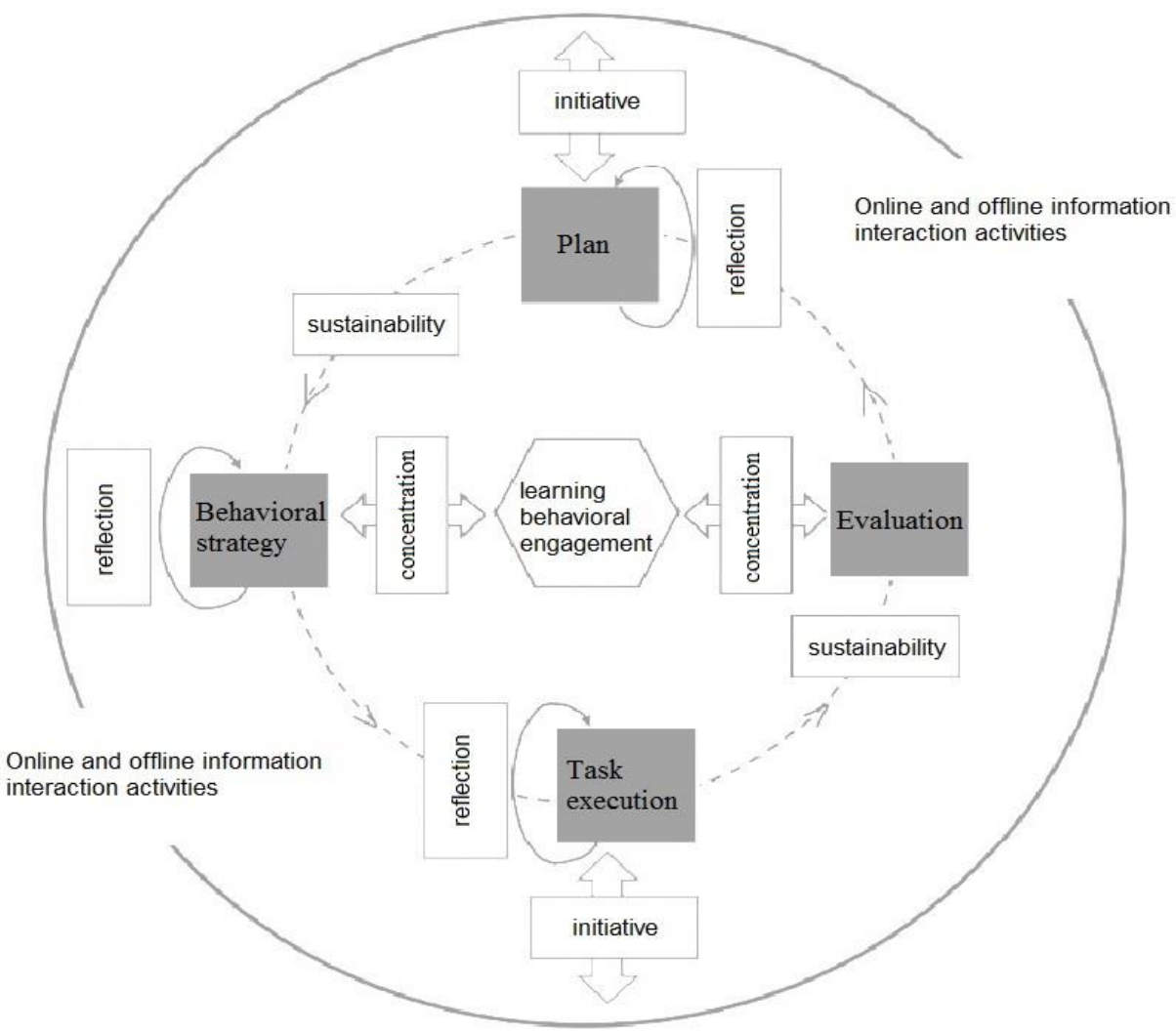

Figure 2. Learning behavioral engagement periodic feedback model

The periodic feedback model defines the dimensions of sustainability, initiative, reflection and concentration to represent the level of learning behavioral engagement. The model includes three levels: learning behavioral engagement, periodic feedback and information exchange activity.

The core level at the center of the circle is the input of learning behavioral engagement. From the result of learning, the transformation of the new and old concepts and the change of cognitive structure of learners are embodied. The middle layer is the periodic feedback layer (the ring mark of the dotted arrow). As an intermediate variable, it points directly to individual learning and generates and maintains high learning behavioral engagement. The outermost level is information exchange activity layer. Information exchange activities are the continuous cohesion and reorganization of learning behavioral sequence under the influence 
Sun, Bin / Construction of Learning Behavioral Engagement Model for MOOCs Platform Based on Data Analysis.

of subject, object, community, intermediary, tool, mixed learning environment and other factors to meet the learning needs purposefully.

The internal interaction mechanism of the model includes four aspects. The interaction between the core layer and the middle layer is embodied in the regulation of periodic feedback and learning behavioral engagement. Continuous flow within the middle layer is embodied in the four elements of "sustainability" connection with plan, behavioral strategy, task execution and evaluation. The reorganization and changes of the elements in the middle layer reflect the "reflection" control over the plans, behavioral strategy and task execution. The interaction between middle layer and information exchange is embodied in "initiative" to regulate periodic feedback and information exchange activities.

Based on the proposed model, the relationship between different engagement factors and learning outcomes can be examined. Factor analysis is used to extract the principal components of variables, regression method is used to calculate and store the scores of each factor, and the correlation coefficients between the scores of each factor and the learning results are calculated. Through all-data analysis, the correlation coefficients are shown in Table 4.

Table 4

Correlation Coefficient Between Four Factor Scores and Learning Outcomes

\begin{tabular}{lcc}
\hline Factor & $\boldsymbol{r}_{\boldsymbol{s}}$ & $\mathbf{P}$ \\
\hline Sustainability & 0.09 & 0.012 \\
Initiative & 0.11 & 0.003 \\
Concentration & 0.28 & 0.001 \\
Reflection & 0.52 & 0.000 \\
\hline
\end{tabular}

From Table 4 we can see that the scores of the four factors were significantly correlated with learning outcomes. "sustainability" factor and "initiative" are low correlated with learning outcomes $(0.09<\mathrm{r}<0.11)$. "concentration" factor and "reflection" are middle correlated with learning outcomes $(0.28<\mathrm{r}<0.52)$.

Regression analysis was used to investigate the explanatory degree of each dimension to the learning results with four factor scores as independent variables and learning results as dependent variables. Collinearity diagnosis was made by Tolerance, VIF and CI. It is found that there was no multivariate collinearity between predictive variables. The $\mathrm{P}$ value of the regression model is 0.000 , which is less than 0.05 . It indicates that the variance of the whole interpretation of the regression model reaches a significant level, and the regression effect of the model is remarkable. The normalization coefficients of the four independent variables are positive, which indicates a significant positive impact on learning outcomes.

Combining the results of factor analysis and principal component regression, we can see that according to "dimension-activity-index" the proposed learning behavioral engagement periodic feedback model is reasonable, and it can better represent learning behavioral engagement.

\section{Conclusion}

At present, the evaluation framework of earning behavioral engagement based on MOOC is still relatively scarce. In the MOOC platform, the development of learning activities depends on learners' interests, time and 
Sun, Bin / Construction of Learning Behavioral Engagement Model for MOOCs Platform Based on Data Analysis.

preferences. In this paper, the evolutionary process of learning behavior involvement can be analyzed in three stages. Essentially, it is the result of learners' constant adjustment of information exchange activities and the adaptive adjustment of learning behavior based on the dual supply of online and offline education. Based on the above analysis, a large-scale empirical data analysis was developed, and a learning behavioral engagement periodic feedback model is constructed. Through the analysis of the engagement evaluation framework, the rationality and higher explanatory power of the evaluation dimension are verified.

\section{References}

Bakker, A. B., Vergel, A. I. S., \& Kuntze, J. (2015). Student engagement and performance: A weekly diary study on the role of openness. Motivation \& Emotion, 39(1), 49-62. http://dx.doi.org/10.1007/s11031-0149422-5

Finn, J. D. (1989). Withdrawing from school. Review of Educational Research, 59(2), 117-142. http://dx.doi.org/10.2307/1170412

Fredricks, J. A., Blumenfeld, P. C., \& Paris, A. H. (2004). School engagement: Potential of the concept, state of the evidence. Review of Educational Research, 74(1), 59-109. http://dx.doi.org/10.3102/00346543074001059

George D. Kuh. (2003). What we're learning about student engagement from NSSE: Benchmarks for effective educational practices. Change, 35(2), 24-32. http://dx.doi.org/10.1080/00091380309604090

Hamane, A. C. (2014). Student engagement in an online course and its impact on student success. Dissertations \& Theses - Gradworks.

Hammond, M. (2014). Introducing ICT in schools in England: Rationale and consequences. British Journal of Educational Technology, 45(2), 191-201. http://dx.doi.org/10.1111/bjet.12033

Hughes, G., \& Dobbins, C. (2015). The utilization of data analysis techniques in predicting student performance in massive open online courses (MOOCS). Research \& Practice in Technology Enhanced Learning, 10(1), 10. http://dx.doi.org/10.1186/s41039-015-0007-z

Ladd, G. W. (1997). The teacher-child relationship and children's early school adjustment. Journal of School Psychology, 35(1), 61-79. http://dx.doi.org/10.1016/S0022-4405(96)00029-5

Lam, S. F., Jimerson, S., Wong, B. P., Kikas, E., Shin, H., \& Veiga, F. H. (2014). Understanding and measuring student engagement in school: the results of an international study from 12 countries. School Psychology Quarterly, 29(2), 213-232. http://dx.doi.org/10.1037/spq0000057

Leng, J., Wu, X., \& Gu, X. (2017). Research on the deep learning online course activity design: Based on case analysis to the open university of UK. Journal of Distance Education, 35(2), 56-65.

Li, Y., \& Lerner, R. M. (2013). Interrelations of behavioral, emotional, and cognitive school engagement in high school students. Journal of Youth \& Adolescence, 42(1), 20-32. http://dx.doi.org/10.1007/s10964-0129857-5

Liu, M., Calvo, R. A., Pardo, A., \& Martin, A. (2015). Measuring and visualizing students' behavioral engagement in writing activities. IEEE Transactions on Learning Technologies, 8(2), 215-224. http://dx.doi.org/10.1109/TLT.2014.2378786 
Luo, W., Hughes, J. N., Liew, J., \& Kwok, O. (2009). Classifying academically at-risk first graders into engagement types: association with long-term achievement trajectories. Elem Sch J, 109(4), 380-405. http://dx.doi.org/10.1086/593939

Mahatmya, D., Lohman, B. J., Matjasko, J. L., \& Farb, A. F. (2012). Engagement across developmental periods. High School Reform and Student Engagement, 45-63. http://dx.doi.org/10.1007/978-1-4614-2018-7_3

Martin, A. J. (2011). Examining a multidimensional model of student motivation and engagement using a construct validation approach. British Journal of Educational Psychology, 77(2), 413-440. http://dx.doi.org/10.1348/000709906X118036

Miles, S. B., \& Stipek, D. (2006). Contemporaneous and longitudinal associations between social behavior and literacy achievement in a sample of low-income elementary school children. Child Development, 77(1), 103117. http://dx.doi.org/10.1111/j.1467-8624.2006.00859.x

Mosher, R., \& Macgowan, B. (1985). Assessing student engagement in secondary schools: Alternative conceptions, strategies of assessing, and instruments. Academic Achievement, 44.

Nicart, E., Zanuttini, B., Grilhères, B., Giroux, P., \& Saval, A. (2017). Using reinforcement learning to continuously improve a document treatment chain, Revue d'Intelligence Artificielle, 31(6), 619-648. http://dx.doi.org/10.3166/RIA.31.619-648

Ouimet, J. A., \& Smallwood, R. A. (2005). Assessment measures: Classe--the class-level survey of student engagement. Assessment Update, 17, 13-15.

Reeve, J. (2012). A self-determination theory perspective on student engagement. Handbook of Research on Student Engagement. Springer US. http://dx.doi.org/10.1007/978-1-4614-2018-7_7

Rose-Krasnor, L. (2010). Future directions in youth involvement research. Social Development, 18(2), 497-509. http://dx.doi.org/10.1111/j.1467-9507.2008.00506.x

Skinner, E. A., Kindermann, T. A., \& Furrer, C. J. (2009). A motivational perspective on engagement and disaffection: Conceptualization and assessment of children's behavioral and emotional participation in academic activities in the classroom. Educational \& Psychological Measurement, 69(3), 493-525. http://dx.doi.org/10.1177/0013164408323233

Skinner, E., Furrer, C., Marchand, G., \& Kindermann, T. (2008). Engagement and disaffection in the classroom: part of a larger motivational dynamic?. Journal of Educational Psychology, 100(4), 765-781. http://dx.doi.org/10.1037/a0012840

Uztosun, M. S., Skinner, N., \& Cadorath, J. (2017). An action research study into the role of student negotiation in enhancing perceived student engagement during english speaking classes at university level in Turkey. Educational Action Research, 26(1). http://dx.doi.org/10.1080/09650792.2016.1270223 